International Journal on Cybernetics \& Informatics (IJCI) Vol. 5, No. 2, April 2016

\title{
Hexagonal Circularly Polarized Patch ANTENNA FOR RFID APPLICATIONS
}

\author{
Prakash K.C, Vinesh P.V., Jayakrishnan M.P., Dinesh R., Mohammad Ameen and \\ Vasudevan K.
}

Center for Research in Electromagnetics and Antennas (CREMA), Dept. of Electronics, Cochin University of Science and Technology, Kochi-22, Kerala, India.

keyceepeelgmail.com

\begin{abstract}
A compact design of a hexagonal single feed circularly polarized microstrip antenna for RFID applications is proposed. This structure fabricated on FR4 substrate offers compactness, good axial ratio bandwidth with a broadside radiation characteristic in the entire band, better gain, good impedance bandwidth at a resonant frequency of $2.45 \mathrm{GHz}$. The structure is suitable for RFID reader antenna applications.
\end{abstract}

\section{KEYWORDS}

RFID, Hexagonal Patch, CP, Elliptical Slot \& RHCP.

\section{INTRODUCTION}

There are a lot of advantages for circularly polarized (CP) antenna which make it attractive for many wireless systems. As strict orientation between receiving and transmitting antenna is not required, this avoids false identification of targeted objects by RFID readers and hence no polarization mismatch losses. The CP antenna is very effective in combating multi path effects. A single co-axial fed circularly polarized antenna is proposed in this work. It is simple in its structure than dual-fed ones and the generated mode is usually excited in an electrically thin cavity region of the microstrip antenna. The circularly polarized radiation is generated by the effect of asymmetries or perturbation segments in the patch. Various perturbation methods have been adopted in literature for designing a single feed circularly polarized microstrip antenna. Truncating the corners of the hexagonal patch and inserting slits[1], One ' $\mathrm{V}$ ' shaped slot embedded into a cross shaped rectangular patch antenna[2], asymmetric-circular shaped slotted microstrip patch antennas with slits[3], two crossed PIFA[4], a cross-strip embedded along the Xshaped slot for a proximity-fed technique [5], antenna using a set of slits and slots[6], a cross slot embedded on the radiating patch[7], truncating corners of a square patch and inserting slits of different lengths at the edges of a square patch [8,9], two slits inserted at the annular-ring patch[10], embedding a circular central elliptical slot on a circular patch [11], truncating the corners of a polygonal patch are some of the techniques employed to radiate circularly polarized waves. In this structure, a hexagonal microstrip patch antenna with the perturbation technique of embedding a central elliptical slot and two circular slots is proposed. The dimensions of the patch and slots and the feed point location are extremely important and optimized for good performance. It exhibits good circular polarization radiation characteristics.

\section{ANTENNA GEOMETRY}

The proposed antenna geometry consists of regular hexagonal patch with a central elliptical slot and two circular slots; one on the right side and the other on the left side of the elliptical slot. It is fabricated on an FR4 substrate with a dielectric constant 4.4, thickness $1.6 \mathrm{~mm}$ and a $\tan \delta=0.02$. As depicted in Figure 
1, the elliptical slot is situated on the center of the patch oriented along the $\mathrm{X}$ axis. The dimensions of the elliptical slot are designated as $\boldsymbol{b}$ the major radius (base radius), the secondary radius $\boldsymbol{c}$ and the aspect ratio $\boldsymbol{k}$ the ratio of $\boldsymbol{c}$ to $\boldsymbol{b}$. The radius of the circular slot $\boldsymbol{r}_{\boldsymbol{a}}$ is chosen to be $3 \mathrm{~mm}$.

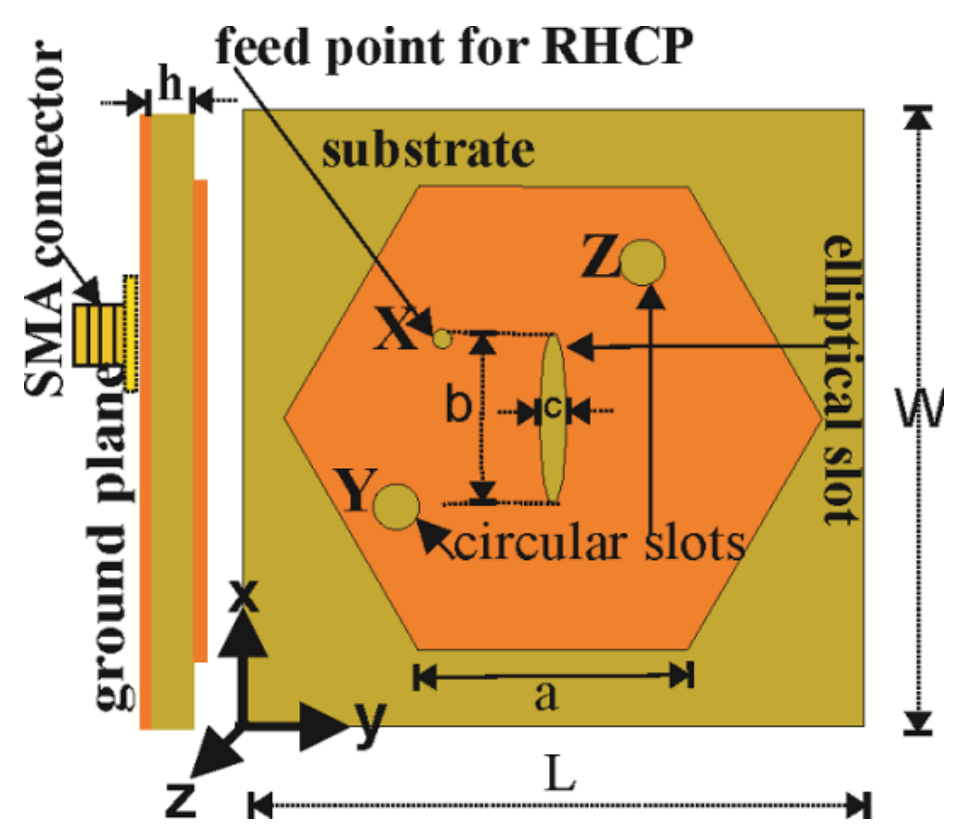

(a)

(b)

Figure 1 . Geometry of the proposed antenna. 1(a) side view and 1 (b) Top view, $a=17.52 \mathrm{~mm}, b=$ $11.2 \mathrm{~mm}, \mathrm{c}=0.84 \mathrm{~mm}, \mathrm{k}=0.15, \mathrm{~L}=\mathrm{W}=40.4 \mathrm{~mm}$, guide wavelength $\lambda \mathrm{g}=0.0606 \mathrm{~m}, \varepsilon_{\text {reff }}=$ $4.087, \mathrm{X}(25.4 \mathrm{~mm}, 13 \mathrm{~mm}), \mathrm{ra}=3 \mathrm{~mm}, \mathrm{Y}(14.4 \mathrm{~mm}, 10 \mathrm{~mm}, 1.6 \mathrm{~mm}) \mathrm{Z}(30.4 \mathrm{~mm}, 26 \mathrm{~mm}, 1.6 \mathrm{~mm})$

In this structure, elliptical and the circular slots are chosen as the detuning elements to split the fundamental TM11 mode to two orthogonal modes TM01 and TM10 [11]. The dimensions of the elliptical and circular slots are so crucial that it affects the radiation of circularly polarized waves. The antenna is excited through co-axial probes at the feed location $\mathrm{X}$ to give circularly polarized electromagnetic radiation in the clockwise direction, i.e., Right Handed Circular Polarization (RHCP). The feed point is chosen along the locus of $50 \Omega$ characteristic impedance and is adjusted for good matching. The photograph of the proposed antenna is depicted in Figure 2.

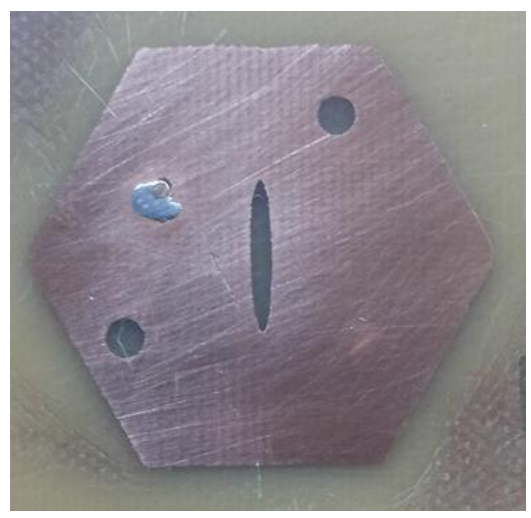

Figure 2. Photograph of the antenna prototype 


\section{DESIGN}

As the circular patch and hexagonal patch are closely related to each other, the design of a circular patch is considered for the design of a hexagonal patch antenna [12].

Then by equating the areas of a circle and a regular hexagon, the edge or side length of the regular hexagon a may be found [12] out as,

$\mathrm{a}=\mathrm{r}_{\mathrm{e}} \sqrt{ } \frac{2 \pi}{3 \sqrt{3}}(1)$

By the proper selection of the feed point, the dominant mode is detuned into two equal amplitude orthogonal degenerate modes, orthogonal even mode $\mathrm{TM}_{e}$ and orthogonal odd mode $\mathrm{TM}_{\mathrm{o}}$, without considering the higher order modes. By introducing the asymmetry, the resonant frequencies of two degenerate modes are made nearly equal.

The normalized impedance ratio of the detuned modes is a complex number, which has a magnitude part and phase part. The phase part corresponds to the phase difference of the CP field components, while the magnitude is proportional to the axial ratio. The angle is designed to be 900 and the magnitude to be less than $3 \mathrm{~dB}$. Thus the criterion for circular polarization is satisfied. By selecting appropriate dimensions for the slot, the two degenerate mode frequencies are made nearly equal.

By introducing the asymmetry due to the central elliptical slot and the two circular slots, the dominant mode of the patch is detuned into two orthogonal degenerate modes, the odd mode and the even mode. The odd mode is oriented about the $\mathrm{X}$ axis and the even mode is oriented about the $\mathrm{Y}$ axis. The odd mode suffers minimum perturbation due to the elliptical slot. As the fundamental mode exhibits a zero in this area, the fields will not be affected significantly. If the slot had been a rectangular geometry with no change in orientation, the odd mode surface current would not have been affected by this perturbation and the resonant angular frequency would have been approximately same as that of the fundamental resonant frequency. In the even mode (oriented about the $\mathrm{Y}$ axis), the surface current is forced to traverse more length around the elliptical and circular slots and hence the resonant frequency $\omega$ e e is reduced. If a second orthogonal cut is made at the center [13], it will enhance the electrical path of the odd mode and the corresponding resonant frequency will be reduced. Here in this proposed structure, the effect of more electrical length is achieved by the two circular slots and the appropriate dimension of secondary radius for the elliptical slot. Thus the odd mode resonant frequency $\omega_{-} \mathrm{o}$ is reduced. Thus surface currents in both odd mode and even mode are reduced. The dimensions of the slots have a major role in determining the resonant frequency for both the modes. The overall dimension of the antenna decreases, which results in the same central frequency for the two modes. It was demonstrated in [14] that with annular shapes it is possible to enhance the bandwidth because less amount of stored energy is stored beneath the patch metallization and quality factor is thereby reduced. Both the effects of splitting of TM11 mode into orthogonal modes TM01 and TM10 and enhancement of bandwidth due to annular shape can be achieved by introducing an elliptical slot on the center of the patch and two circular slots on both sides. A mandatory condition for achieving circular polarization is equal amplitude and 900 out of phase for the degenerate modes. By selecting proper slot dimensions and feed location, the two modes are made equal in amplitude and a phase difference of 900 between them. This results in circular polarized radiation. Thus the perturbation produced by the elliptical slot and circular slots gives rise to mode degeneration. The overall resonant frequency is reduced. The edge of the hexagonal patch is designed for a resonant frequency of $2.63 \mathrm{GHz}$. Due to the elliptical and circular slots the resonant frequency is reduced to 2.45 $\mathrm{GHz}$ and thus the overall dimension is reduced by a factor of $18.10 \%$.

To design the hexagonal patch, design equations are derived based on the geometry and the frequency of operation after computing the guide wavelength $\lambda \mathrm{g}$, that is the wavelength in the dielectric given by, 


$$
\lambda_{\mathrm{g}}=\frac{\lambda_{0}}{\sqrt{\varepsilon_{\text {reff }}}}
$$

where $\lambda_{0}$ is the free space wavelength at $2.45 \mathrm{GHz}$ and the effective permittivity of the substrate $\varepsilon_{\text {reff }}$ is computed as 4.106, using the formula in [15] as,

$$
\varepsilon_{\text {reff }}=\varepsilon_{\mathrm{r}}-\frac{\mathrm{C}_{\mathrm{r}} \varepsilon_{\mathrm{r}}}{2}\left(\frac{2 \mathrm{~h}}{\mathrm{x}}+\frac{\mathrm{h}^{2}}{\mathrm{x}^{2}}\right)
$$

where $\boldsymbol{C}_{\mathrm{r}}=0.7$, being a thin substrate, $\boldsymbol{x}$ is the radius of the circumscribed circle - the circle in which the hexagon is inscribed- and $h$ is the height of the substrate.

\section{RESUlTS AND DisCUSSION}

\subsection{Reflection characteristics}

Using the computed parameters, the antenna was simulated using Ansys HFSS 13.0 and tested using ZVB20 vector network analyzer. Optimum feed point was chosen for the best impedance matching of the antenna. The measured and simulated reflection characteristics of the proposed antenna at the co- axial feed point $X$ are plotted in Fig.3. The fundamental resonant frequency of the antenna without slots is 2.63 $\mathrm{GHz}$, whereas with slot the simulated resonant frequency is $2.45 \mathrm{GHz}$.

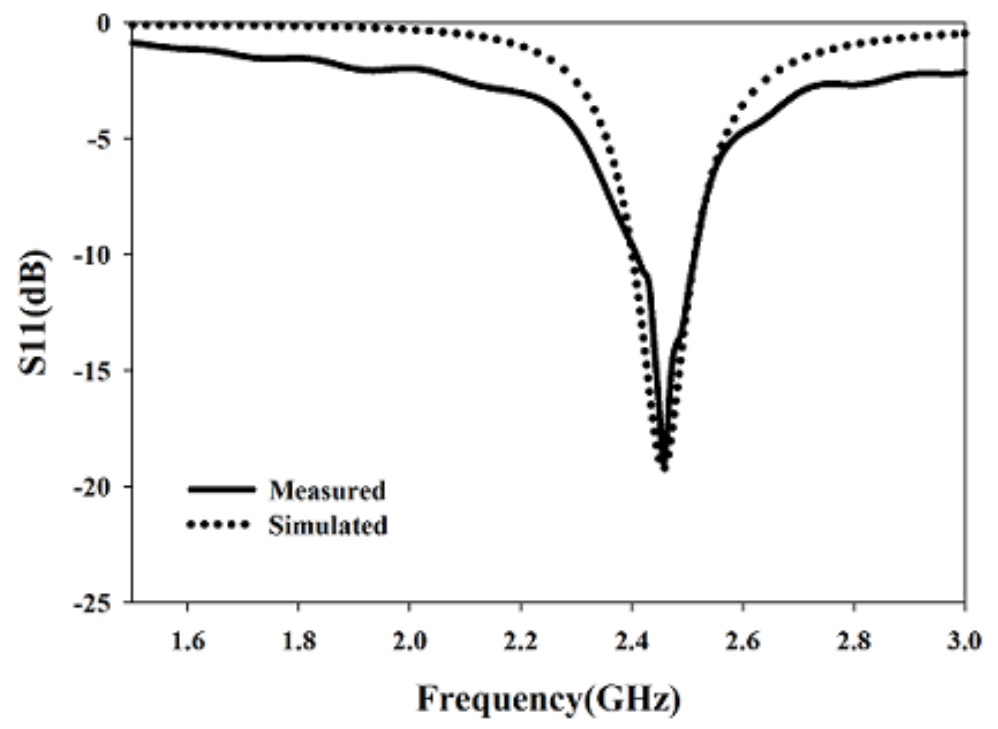

Figure 3. S11 plot of the proposed structure.

\subsection{Axial ratio}

The axial ratio is the magnitude of the normalized impedance ratio (the ratio of two detuned modes). Simulation results show that for various values of aspect ratio $\mathbf{k}$ (the ratio of secondary radius to base radius), the value of minimum axial ratio varies. It is observed that when $\mathbf{k}$ exceeds 0.08 , axial ratio becomes less than $3 \mathrm{~dB}$ and hence circular polarization radiation is exhibited. The $\mathrm{CP}$ radiation at $\mathbf{k}=0.15$ is confirmed from the simulated axial ratio graphs shown in Figure 4, where the necessary criterion for $\mathrm{CP}$, the axial ratio $<3 \mathrm{~dB}$ is satisfied. 


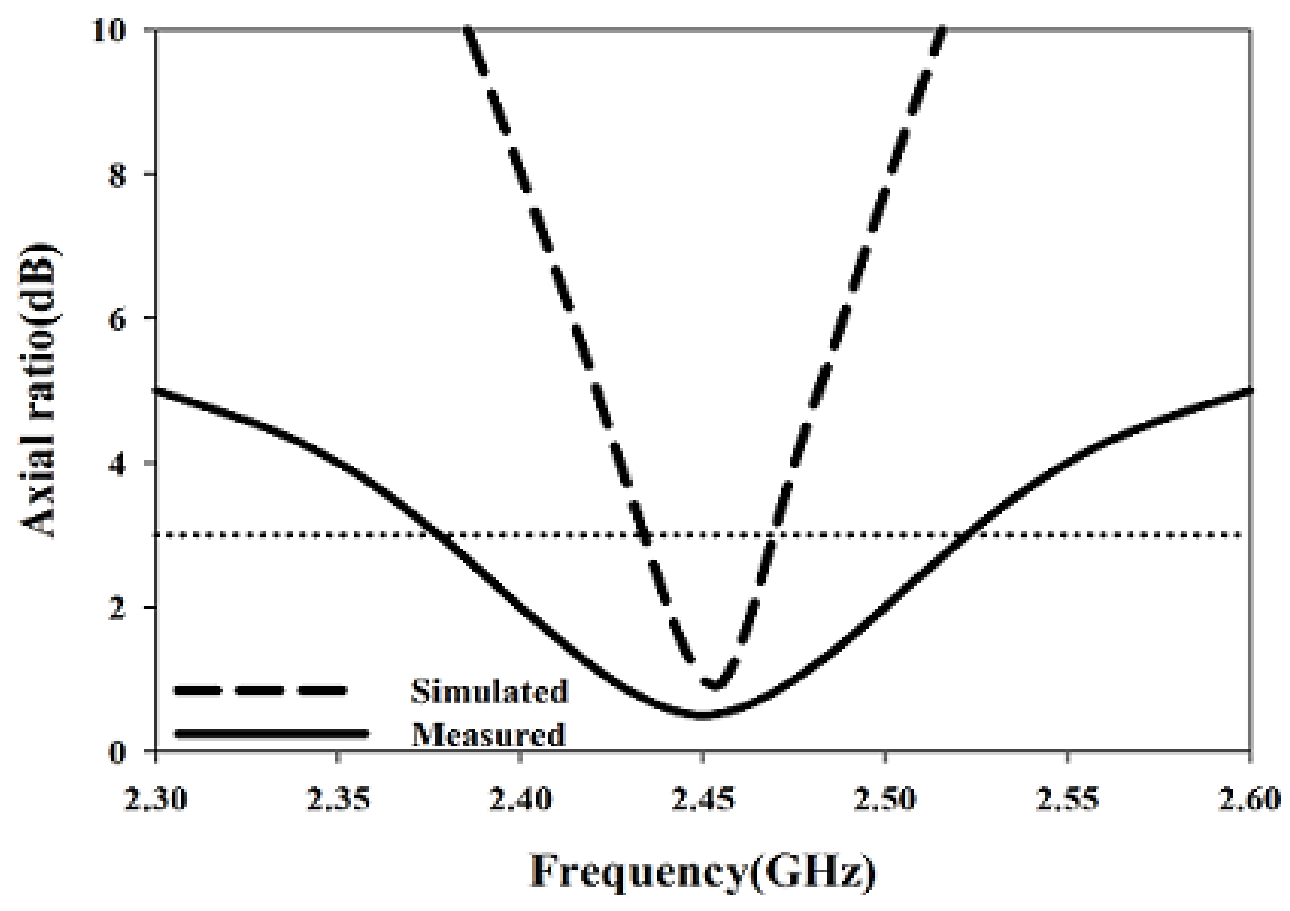

Figure 4. Axial ratio plot

\subsection{Surface current distribution}

The surface current distribution simulated at the center frequency of $2.45 \mathrm{GHz}$ is plotted in Figure 5 . Surface current distribution at $\varphi=0^{0}$ is equal in magnitude and opposite in direction to that at $\varphi=180^{\circ}$. Same is the case of surface current distribution at $\varphi=90^{\circ}$ and $\varphi=270^{\circ}$ and hence the criterion for CP is satisfied. The direction of rotation of current is clockwise in the $+Z$ axis and the sense of polarization is confirmed as right handed circular polarization.
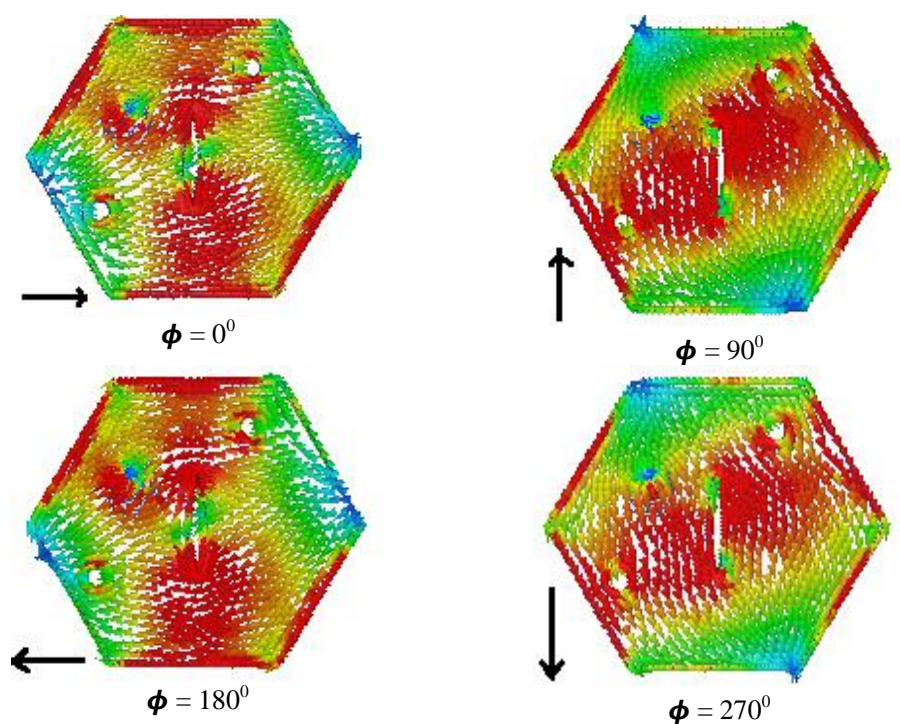

Figure 5. Surface current distribution of the proposed antenna 


\subsection{Radiation pattern}

The measured radiation patterns of the proposed antenna in XZ and YZ planes for $\varphi=0^{\circ}$ and $90^{\circ}$ are plotted in Figure 6. The pattern gives a $3 \mathrm{~dB}$ beam width of $80^{\circ}$.

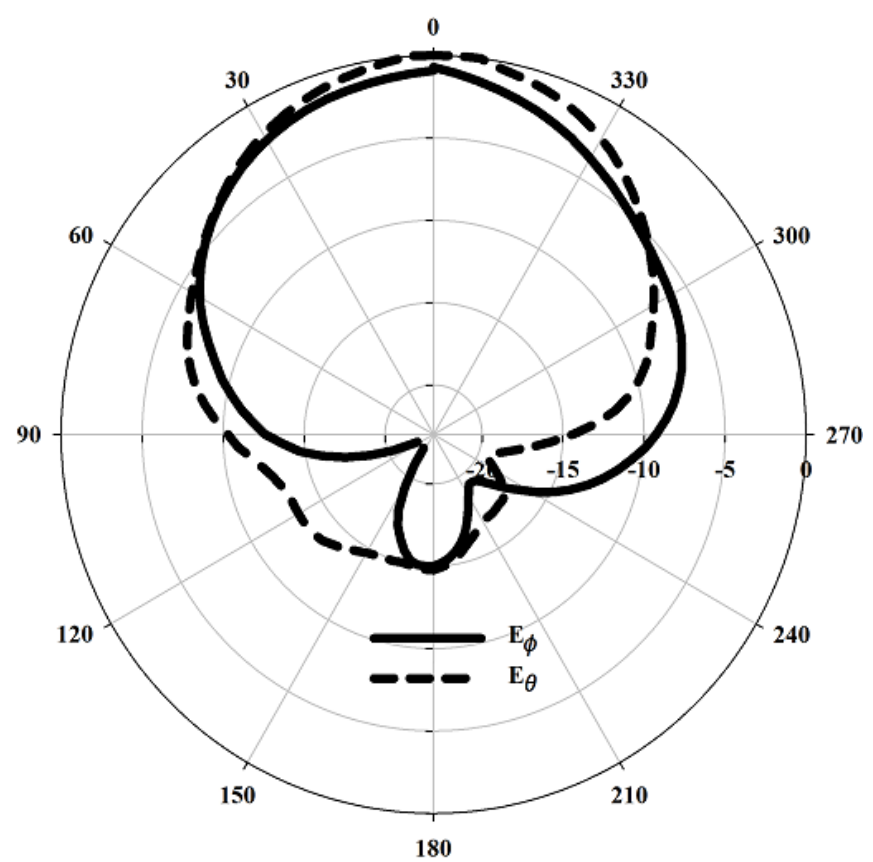

(a)

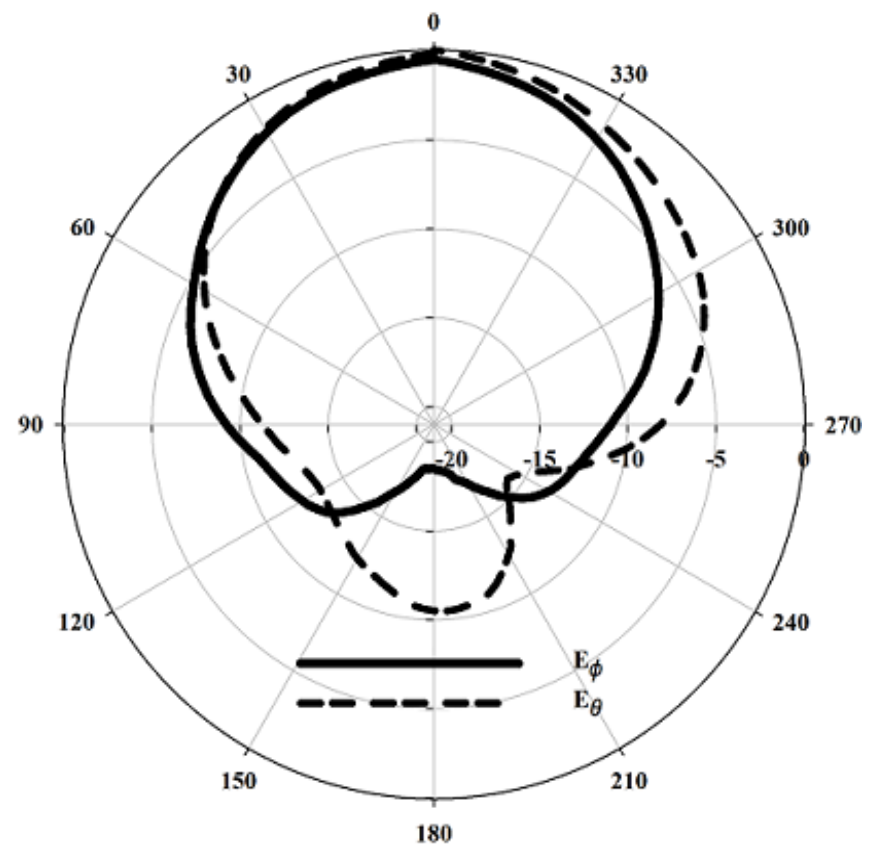

(b) 
Figure 6. Radiation pattern of the antenna in (a) XZ plane (b) YZ plane

\subsection{Gain}

The gain of the antenna is measured using gain comparison method and the measured value is $4.5 \mathrm{dBi}$ at $2.45 \mathrm{GHz}$.

\subsection{Smith chart}

The simulated Smith chart is depicted in Figure7.The dip in it corresponds to the center frequency 2.45 $\mathrm{GHz}$ indicates the excitation of two orthogonal degenerate modes, justifying the circularly polarized radiation.

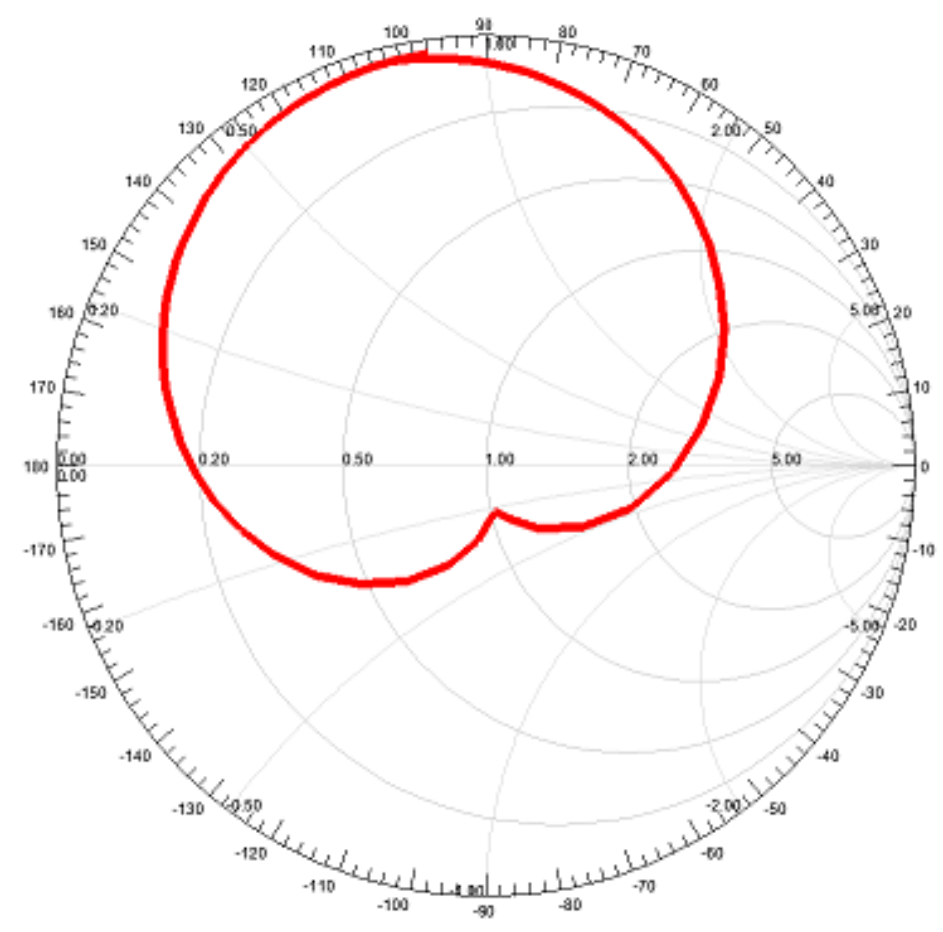

Figure 7. Smith chart

The measured values of the antenna are compared with the circular patch antenna with elliptical slot [11] and tabulated in Table 1.

Table 1. Comparison of measured values

\begin{tabular}{|l|l|l|}
\hline Parameter & $\begin{array}{l}\text { Circular patch antenna } \\
\text { with elliptical slot [11] }\end{array}$ & Proposed antenna \\
\hline Center frequency & $2.45 \mathrm{GHz}$ & $2.45 \mathrm{GHz}$ \\
\hline Return loss & $19 \mathrm{~dB}$ & $19 \mathrm{~dB}$ \\
\hline Gain & $3.85 \mathrm{dBi}$ & $4.5 \mathrm{dBi}$ \\
\hline Minimum axial ratio & $0 \mathrm{~dB}$ & $0.5 \mathrm{~dB}$ \\
\hline Axial ratio bandwidth & $30 \mathrm{MHz}(1.22 \%)$ & $143 \mathrm{MHz}(5.8 \%)$ \\
\hline 10dBimpedance bandwidth & $130 \mathrm{MHz}(5.3 \%)$ & $100 \mathrm{MHz}(4.08 \%)$ \\
\hline
\end{tabular}


International Journal on Cybernetics \& Informatics (IJCI) Vol. 5, No. 2, April 2016

\begin{tabular}{|l|l|l|}
\hline $3 \mathrm{~dB}$ beamwidth & - & $80^{0}$ \\
\hline Area reduction & $9.5 \%$ & $18.06 \%$ \\
\hline
\end{tabular}

\section{Conclusions}

A novel design of a single feed circularly polarized hexagonal patch antenna has been designed, simulated and experimentally investigated. The elliptical and circular slots perturbation method yields better circular polarization characteristics. The experimental results confirm that it is suitable for RFID applications in the $2.45 \mathrm{GHz}$ band.

\section{ACKNOWLEDGEMENTS}

The authors would like to acknowledge the University Grants Commission (UGC), Sree Ayyappa College, Travancore Devaswom Board Management, University of Kerala and Cochin University of Science and Technology for facilitating an opportunity for research under the Faculty Development Programme of UGC.

\section{REFERENCES}

[1] K. Qian \& X. Tang (2011), “Compact LTCC dual - band circularly polarized perturbed hexagonal microstrip antenna," IEEE Antennas and Wireless Propag. Lett., vol. 10, ,pp. 1212 -1215.

[2] M. S. Nishamol, V. P. Sarin, D. Tony, C. K. Aanandan, P. Mohanan, \& K. Vasudevan, (2011) "Design Of A Circularly Polarized Rectangular Microstrip Antenna for GPS Applications," Microwave and Optical Technology Letters, vol. 53, no. 2, pp. 468-470.

[3] Nasimuddin, Z. N. Chen \& X. Qing, (2010), "Asymmetric-circular shaped slotted microstrip antennas for circular polarization and RFID applications," IEEE Trans. Antennas Propag., vol. 58, no. 12, 2010, pp. 3821-3828.

[4] S.Pflaum, F. Canneva, P. Le Thuc, G. Kossiavas \& R. Staraj, (2013) “ PIFA antenna with tilted circular polarization angle for RFID readers," IEEE Antennas Propag. Soc. AP-S Int. Symp.,,pp. 1734-1735.

[5] Horng-Dean Chen, Shang-Huang Kuo, Chow- Yen- Desmond Sim \& Ching-Han Tsai (2012) "CouplingFeed Circularly Polarized RFID Tag Antenna Mountable on Metallic Surface," IEEE Transactions on Antennas and Propagation, vol. 60, no. 5.

[6] D. L. Nguyen, K. S. Paulson \& N. G. Riley, (2012) "Reduced-size circularly polarised square microstrip antenna for $2.45 \mathrm{GHz}$ RFID applications," IET Microwaves, Antennas Propag., vol. 6, no. 1, p. 94.

[7] J.S. Row \& C.Y. Ai,(2004) "Compact Design Of Single Feed Circularly Polarized Microstrip Antenna",Electronic Lett 401093-94.

[8] W.S. Chen, C.K. Wu \& K.L. Wong, (2001) “ Novel Compact Circularly Polarized Square Microstrip Antenna", IEEE Trans on Antennas and Propagation, 49, 340-342.

[9] J.S. Roy \& M. Thomas, (2008), "Design of a circularly polarized microstrip antenna for WLAN", Prog Electromagnetics, Res 3, pp: 79-84.

[10] S. S. Gao, Q. Luo, \& F. Zhu, (2014) Circularly Polarized Antennas John Wiley \& Sons Ltd, United Kingdom..

[11] S.Maddio, A. Cidronali \& G. Manes, (2011) "A New Design Method For Single- Feed Circular Polarization Microstrip Antenna With An Arbitrary Impedance Matching Condition”, IEEE Transactions on Antennas and Propagation., vol. 59, no. 2, pp. 379-389. 
[12] Nagendra Kushwaha \& Raj Kumar,(2013)" Design Of Slotted Ground Hexagonal Microstrip Patch Antenna And Gain Improvement With FSS Screen" Progress In Electromagnetics Research B, vol. 51, pp: 177-199.

[13] Horng- Dean Chen, Shang-Huang Kuo, Chow- Yen- Desmond Sim \& Ching-Han Tsai, (2012)

"Coupling-Feed Circularly Polarized RFID Tag antenna Mountable on Metallic Surface," IEEE

Transactions on Antennas and Propagation, vol. 60, no. 5,Pages: 2166 - 2174,

[14] Bhattacharyya, A. \& L. Shafai, "A Wider Band Microstrip Antenna For Circular Polarization," IEEE Transactions on Antennas and Propagation, vol. 36, no. 2, pp 157-163.

$(1988)$

[15] Ramesh Garg, Prakash Bhartia, Inder Bahl \& Apisak Ittipiboon, (2001) Microstrip Antenna Design Handbook, Artech House, London.

\section{AUTHORS}

Prakash K.C was born in the year1970. He passed his M.Sc Degree in Electronics Science from Cochin University of Science and Technology, Kerala, India, in 1993, with third rank.with third rank. He has got 22 years of teaching experience in Electronics and holds the designation of Associate Professor in Sree Ayyappa College, Eramallikkara; a Kerala Govt. Aided college affiliated to the University of Kerala. Currently he is engaged in research under the faculty development programme of UGC, in the area of microwave antennas for RFID applicatios. He has got 1 international journal and four international conference publications to his credit. $\mathrm{He}$ is a Fellow of IETE. His areas of interest include RFID CP antennas, metamaterial, energy harvesting etc.

Vinesh $\mathbf{P} \mathbf{V}$ received the B.Sc. degree in electronics from the University of Kannur, India,and the M.Sc. degree in Electronics fromthe MES College Erumely, Kottayam, India, in 2004 and 2006,respectively. He is currently working towards the Ph.D.degree at Cochin University of Science andTechnology (CUSAT), Kochi, India. His research interests include designing of multiband antennas, planar inverted $\mathrm{F}$ antennas, ZOR antenna etc

Jayakrishnan M.P reeceived the B.Sc. degree in Electronics from the Mahatma Gandhi University, Kottayam, India and M.Sc. degree in Electronics Science from the Cochin University of Science and Technology, Kochi, India, in 2012 and 2014,respectively. He is currently working towards Ph.D. degree in Microwave Electronics at the Cochin University of Science and Technology (CUSAT), Kochi, India. His research interests include Microwave based Bio-Sensors, Implantable Antennas, Frequency Selective surfaces, Metamaterials etc.

Dinesh .R was born in the year1985. He passed his M.Sc Degree in Electronic Sciencefrom Cochin University of Science and Technology in 2005. He has got 6 years of research experience in Microwave field. Currently he is an Assistant Professor at NSS college, Rajakumari, Idukki; a Kerala Govt. Aided college affiliated to the MG University, Kerala. He has got 13 international journal and 15 International conference publications to his credit.
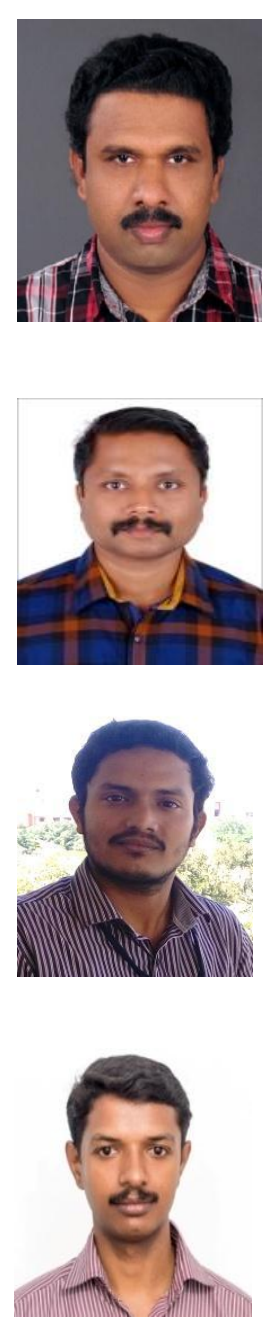
Mohammad Ameen was born in the year 1990. He received the B.Tech degree and M.Tech degree in Electronics and Communication Engineering from Mahatma Gandhi University, kerala, in 2012 and 2014, respectively. He has 1 year of research experience in Microwave field. Currently he is a Senior Research Fellow in CSIR (New Delhi) funded project at Department of Electronics, Cochin University of Science and Technology, Cochin, Kerala. He has got one international journal and four international conference publications to his credit. His research interests include high gain antennas and MIMO antennas.

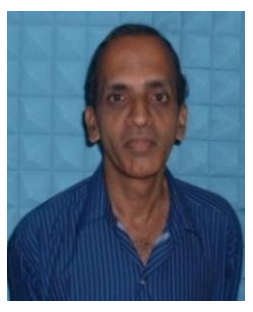

K.Vasudevan took $\mathrm{PhD}$ in 1982 in Microwave antennas and joined as lecturer in Cochin University of science and technology in 1985. He is a professor in this University since 1995. He was head of department of Electronics from 2004 to 2010 and Dean, faculty of technology during 2010 to 2013. Currently, he is a CSIR Emeritus scientist in Cochin University. He has more than 220 publications in International journals and conference proceedings and has more than 1200 citations and an h- index of 19 . He has been an investigator for about 20 major projects from various agencies having a total outlay of 30 crores of rupees. He has chaired and presented papers in several IEEE international conferencesabroad.. $\mathrm{He}$ is a senior member of IEEE and Fellow of IETE.

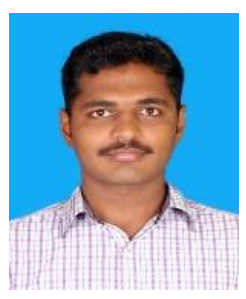

